\title{
How to Design and Apply Interactive Digital Educational TV Programs Based on the ADDIE Model
}

\author{
Zixun Hua
}

\begin{abstract}
The aim of this research is to give an interactive learning resource to undergraduate. At first, there are three research questions: how to 1) design, 2) apply, and 3) test the interactive educational TV program were put forward which is based on the literature review on cognitive load theory, educational television, and interactive digital educational TV program. Alone with the 5 steps of ADDIE model, this research has designed the "Camera basic skills" interactive educational TV program for undergraduate students of SCNU. During the development and application phase, the Interactive Navigation Process (INP) has been chosen to apply the developed interactive TV program. Finally, there is an evaluation index system to test the effective for learning about this interactive educational TV program. After the analysis, the data indicated that the interactive educational TV program has achieved good performance on the three aspects (instruction, interactivity, and technique) of evaluation index system. So that the conclusion that "Camera basic skills" interactive educational TV program is effective for undergraduate students on the three aspects of instruction, interactivity, and technique can be found.
\end{abstract}

Index Terms-ADDIE, digital educational TV program, interactive navigation process, design research.

\section{INTRODUCTION}

Interactive TV is a production of combine the digital TV technology and network technology. Developing the interactive digital educational television programs will help to improve the learners' learning initiative and creativity. ADDIE is a model of instructional systems design (ISD) [1], which has 5 stages that including analyze, design, development, implementation and evaluation. The model is applied to the curriculum or teaching system design general process and using ADDIE model at the design stage to ensure the effectiveness of the development process.

\section{A. Cognitive Load Theory (CLT)}

Television as a visual-audio media, the moving picture, environment like sound, and the linear information are the strengths compare with other media [2]. Just for the communicate process of television is linear communication, the learning process of students can increase their mental effort during their knowledge acquisition [3]. However, the accumulation of mental effort is close to learners' cognitive load that would make the learning attitude of learners tend to negative. Sweller argued that an instructional design can reduce the cognitive load in learners` working memory, so

Manuscript received May 6, 2015; revised July 13, 2015.

Zixun Hua is with the College of Educational Information Technology, South China Normal University, Guangdong, Guangzhou, 510631, China (e-mail: 252408933@qq.com). that the chosen of ADDIE model in this research is necessary [4]. On the other hand, this research will base on the Cognitive Load Theory (CLT) to apply the visual-audio resources which can give an experience both entertain and education during the pedagogy practice. Cognitive Load Theory (CLT) is a kind of learning and instruction theory that in order the knowledge be learnt and stored in student's long-term memory (LTM) to integrate the information into learning activities [5]. To fulfill the purpose of promote students learning and cognition, CLT suggests give the relatively learning tasks with students, and the task enable human being to deal with complex problems [6]. F. Bellotti $e t$ $a l$. found that the iTV program which were applied based on CLT can enable improve the working memory. Along with the above described, this research would give the interaction-orientation resources in the process of instructional design and instructional practice [7].

\section{B. Educational Television}

The emergence of television programs should begin in January 1936, the official sign of the TV was that the world`s first TV transmitting station began to broadcast TV programs by the British Broadcasting Corporation (BBC) in London. In 1996, the United States began high-definition digital TV pilot and from then the TV into the digital age [8]. Chinese digital educational television study start late, many research questions are still in the exploratory stage. D. M. Fu (2007) has studied Chinese Educational TV and found that the educational television development is inevitable from qualitative to the empirical research in the level of theoretical research [9]. On the one hand, educational television transmit process are developing from a single propagation to interactive, mobile, diversified, personalized, high-efficiency and high-effective propagation. On the other hand, educational television is developing from technology-oriented to educational-oriented. In fact, the educational television and computer media is just a tool, computer-aided education research, of course not a substitute for theoretical research and practical exploration of educational television [10]. In the long term, TV and computer are mutually reinforcing, so the integration and diversification application form between educational television and computer network technology will be the future development trend of educational television [11].

\section{Interactive Digital Educational TV Program}

The world's first interactive TV program called "Winky Dink and You" which is made by CBS Channel in 1953. In this program, the viewer needs to use the special tool to connect the dots on the TV screen in order to achieve interactive [12]. J. F. Jensen discussed the type of interactive TV formats and content, he believes that the development 
trend of the television media to interactive digital television is an "evolutionary", rather than "change" [13].

Interactive television programs need to be dependent on the Internet. From the MTC-iTV framework designed by S. C. Wang et al, it is evident that each video has its own interface scripts, and each interface script can download the related video files [14]. Furthermore, those linear video clips playback and select concepts of the previous DVD technology design and optimization [15], also provide the complex structure ideas for the interaction design of digital educational television programs.

Some scholars are also exploring the design principles and strategies of interactive contents during t-learning process. Ekman et al. went on a research on how to design the interactive contents to make more attractive interaction for the future audiences. Based on this research, we can learn that interaction of stories and games can prove the user's learning attention [16]. However, few scholars concerned about the best way to design a new type of interactive services (Daly Jones, 2000). Some researches reveal its necessary to provide timely feedback that must be related to the learning ability of learners during the interactive process [7]. Along with the above described, this research will give a television program which is equip good performance on interactive design and interactive contents.

In the application modes of digital educational television programs, M. X. Huang (2010) proposed that the innovative application modes of digital educational television programs including contents planning, the establish the transmission channels, construct the application platform, t-learning process and the evaluation of propagation effect [17]. Rebeca P. Diaz has established a VOD system which was based on the web2.0 [18]. M. X. Huang found the interactive ways of digital television programs when he analyzed the programs such as BBC and so on. Moreover, he divided it into three categories including enhanced TV combination package design, time-shifting design and integrated interaction design. Along with the above described, interactive television program also need equip the flexibility to support different device, system, and platform.

\section{RESEARCH QUESTIONS}

Based on the study of the status of the T-learning, digital educational television programs, the interactive digital education TV programs at home and abroad, we can find that:

1) How to design an interactive educational television program which can meet the requirement of the learners who are learning the subject of "Television program composition" in SCNU?

2) How to apply the developed interactive television in the teaching process to promote students` television shooting skills?

3) How to test the developed interactive television program is indeed skills effective and attitude positive for students when they have watched the learning resource?

\section{RESEARCH PROCESS}

For essentially, the interactive digital educational TV program is a kind of learning resource. To solve the question that "How to design an interactive educational television program which can meet the requirement of the learners who are learning the subject of "Television program composition" in SCNU?", a formal instructional design method should be taken to design a learning ADDIE refers to a systematic development of teaching methods. This model has been chosen by even all of the instructional design process and indeed very clearly for developers during the developing process. According to the general process of ADDIE, the design process will be divided into five stages, including analysis, design, development, implement and evaluation. Based on the ADDIE flowchart developed by Grafinger \& Deborah (1988), this research has drawn the design ADDIE circle of interactive digital educational television programs [19] resource which is specially good for the development of learners.

For the television program's interactive module as the interactive element need a rationally construction. How to design this construction become the key whether the interaction process is appropriate for learners. Through the phase from design to application, the Interactive navigation process (INP) has been chosen to establish the interactive construct of the television program. The idea of INP is originally from the Interpretative Structural Modeling Method (ISM) which is analysis method to construct an abstract system.

\section{A. Design Interactive Module}

The design phase is that design the interactive process of digital educational television programs.

Elements of the system, namely, the knowledge of the educational television programs, According to a variety of television programs, there is a different point of knowledge, each knowledge point as a system of elements of $G$, during the constructing process of Interactive Navigation Process. Gi as the number of the elements of the system, can code with more complex for different knowledge systems, such as G1-2 that the first part of the knowledge system knowledge, so that you can make discrete elements of the system are more orderly.

When there is relationship between the elements of the system you can use the arrow (Fig. 1), if you want to Learn G1, $\mathrm{G} 2$, the path is from $\mathrm{G} 1$ to $\mathrm{G} 2$, that is $\mathrm{G} 1$ is the basics of $\mathrm{G} 2$, $\mathrm{G} 2$ is the expansion of G1 knowledge and so can be called the $\mathrm{G} 1$ is a higher-level knowledge, G2 knowledge points lower.

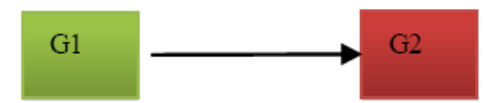

Fig. 1. Knowledge element path.

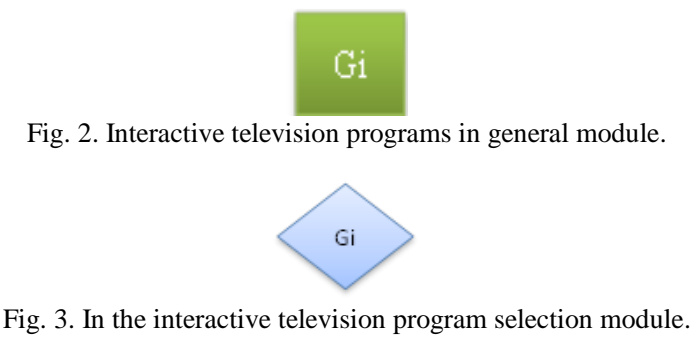

According to the interactive features of the educational television programs, interactive modules can be divided into: 
general module and selected module.

Usually module (Fig. 2) can provide a general learning knowledge unit, having a fixed learning path the way of the learning with a certain direction and in the interactive path diagram can use a cube to represent.

Select the module (Fig. 3) that to provide knowledge of the selected module for learners in educational television program, which is the important part of interactive digital interaction of the educational television programs. It has many units to choose from, generally showing with diamonds.

\section{B. Develop the Interactive Program}

The design of Interactive Navigation Process is the core of the design, even a key part of the entire study. Just like reference digital interactive television ELU interactive system, interpretative structural modeling and social network analysis method (F. Bellotti, 2010), this study proposed digital Interactive Navigation Process of educational television programs (Interactive Navigation Process, INP).

In this study, "Basic essentials of camera using" was chosen as the content of television program which selected from "TV textbook director and production" (see Table I).

\begin{tabular}{|c|c|c|}
\hline No. & The knowledge point / system elements & \\
\hline 1 & Courses introduced & G1 \\
\hline 2 & Students operate and the camera demonstration & G2 \\
\hline 3 & The demonstration of student Reviews & G3 \\
\hline 4 & The demonstration of teachers Comments & G4 \\
\hline 5 & Demo of Video camera is hold by shoulder & G5 \\
\hline 6 & Demo of Video camera is held with tripod & G6 \\
\hline 7 & The introduce of Holding machine & G7 \\
\hline 8 & $\begin{array}{l}\text { The points to note of method about holding } \\
\text { machine and shooting }\end{array}$ & G8 \\
\hline 9 & Basic skill 1 -Flat case & G9 \\
\hline 10 & Basic skill 1_-Flat Explain & G10 \\
\hline 11 & Basic skill $2-$ Stable case & G11 \\
\hline 12 & Basic skill 2-Stable Explain & G12 \\
\hline 13 & Basic skill 3-Quasi- Case & G13 \\
\hline 14 & Basic skill 3_— Quasi- Explain & G14 \\
\hline 15 & The show of Lens focusing & G15 \\
\hline 16 & The explain Lens focusing & G16 \\
\hline 17 & Basic skill 4-Uniform case & G17 \\
\hline 18 & Basic skill 4_-Uniform Explain & G18 \\
\hline 19 & Team drills & G19 \\
\hline
\end{tabular}

TABLE II: RELATIONAL TABLE OF THE ELEMENTS OF THE SYSTEM IN "CAMERA BASIC SKILLS" COURSE

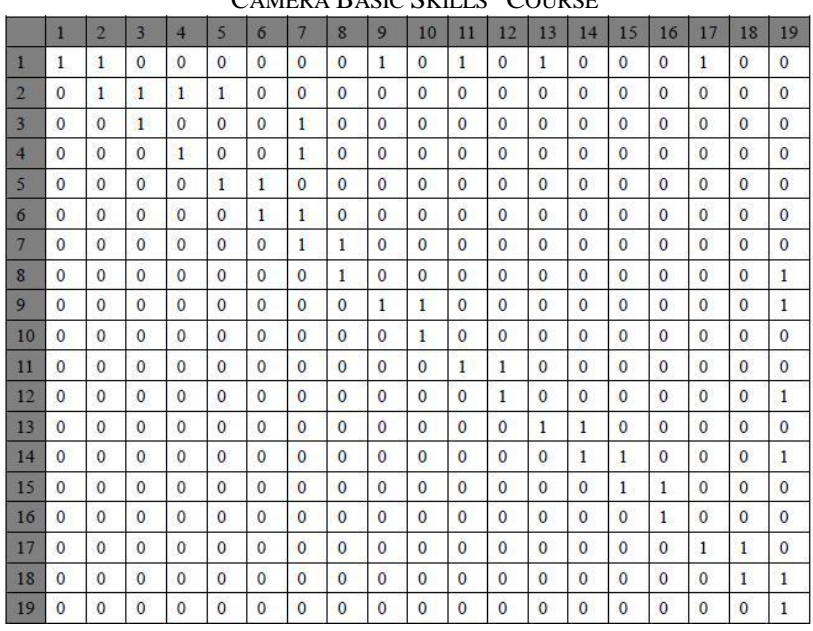

Through investigation to determine the relationship between knowledge points, the numbers of horizontal axis and longitudinal axis in Table II represent the elements of the system of the television program, "0" indicates no relationship, "1" is represented knowledge of the horizontal axis points to the longitudinal axis of knowledge .For example, the number of vertical axis is "1" while "2" is the abscissa number. That is to say, students should learn the knowledge point one before learning knowledge point two. The relational table of specific elements of the system is as follows:

This research has tried to analyze the reachability of matric in relational table of the elements of the system with the matric analysis functions of UCINET software. Finally, we got the reachable matric $\mathrm{M}$ so that we could obtain the overall structure of the elements of system. According to the reachable matric $M=(A+I) \times k+1=(A+I) \times k$, we got the result of the knowledge points relationship. The results are shown in Fig. 2.

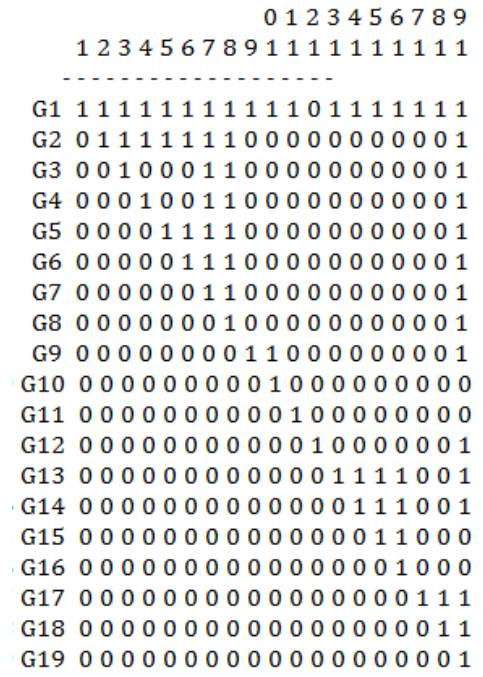

Fig. 4. Reachability schematic diagram of knowledge elements.

To determine the hierarchical relationship of the elements, we had to go on with domain decomposition and inter-stage decomposition after obtaining the reachable matric. With the hierarchical relationship and the distance of knowledge elements, it was easy to draw the Interactive Navigation Process of elements of the system.

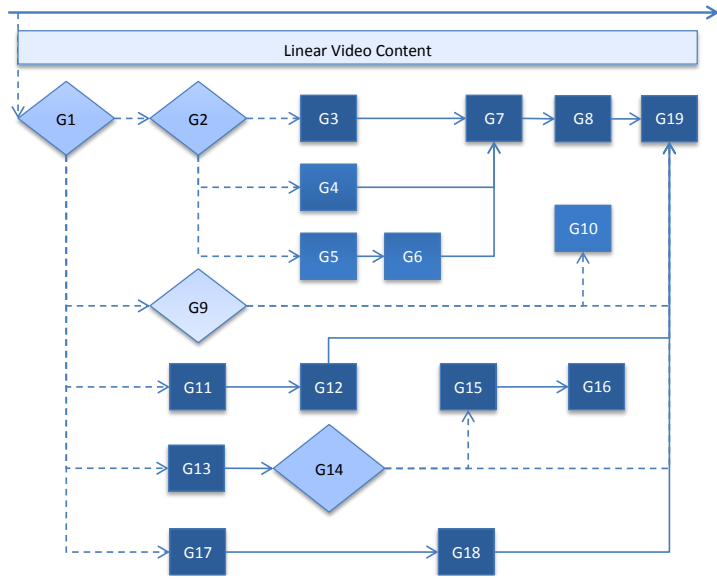

Fig. 5. Interactive digital interactive road map of IDTV

After implementing reachability analysis at analysis stage, the diagram of knowledge elements relationship about "Camera basic skills" was found and the relationship between knowledge points was conducted. So we could draw 
interactive digital interactive road map of IDTV.

Regardless of which way of the interaction we chose, the interactive digital educational TV programs will be different from the traditional television programs, so television resources will not only be limited to video, but it will be available through software of the computer program, Tablet PC applications and set-top boxes program.

This study selected "computer + set-top boxes" as study instruments. Flash technology was used to realize Interactive Navigation Process in digital educational television programs. At the same time, programs were installed in the set-top box for playback.

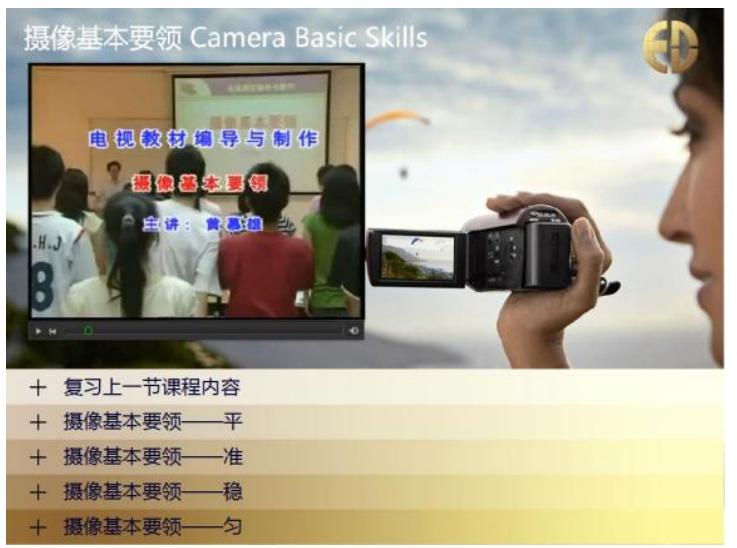

Fig. 6. Interactive TV program "camera basic skills".

\section{Apply the Interactive Program}

For the reason that the objects of this research are originally one class include 15 students, the quasi-experimental research method has been taken to test the pedagogical function of the interactive television program. Quasi-experimental research method is under the condition of non-random to objecting the originally group to apply experiment (K. D. Li, 2001) [20]. As interactive digital educational television programs applied to learner autonomy, the application process preferred to provide multimedia environment for volunteers to watch video rather than apply the program in the process of classroom teaching. Eight male volunteers and seven female volunteers were participated in the research. Entire application stage of the process consists of three steps:

1) Description of the background of the study, as well as the use of Interactive Navigation Process for the volunteers;

2) Volunteers watch the television program "Camera Basic Skills" for 50 minutes;

3) After watching television programs, volunteers were asked to fill in the interactive digital educational TV program quality evaluation questionnaire.

\section{Evaluation}

\section{A. Data Analysis}

According to the characteristics of the interactive digital educational television programs, we selected Analytic Hierarchy Process to construct evaluation index system for Interactive digital educational television program. The evaluation index system consisted of three-level indicator that was instructive, interactive and technological indicators. Then these three indicators were divided into seven secondary indicators. The instructive indicator contained instructional design, education norms, interactive indicator contained interactive design, interactive content and technological indicator contained technological support, technology application, the style of instructional designation. Every secondary indicator was again divided into three individual indicators. In sum, there were a total of 21 individual indicators. We get all levels of indicators weight through academics and students major in TV program filling indicators weighted consult table.

Educational rules are weighted at 58 percentages, and the interactional rules are weighted at 28 percentage. The technological rules are weighted at 14 percentages. All the rules are showed in the following figure:

With the index system of interactive digital television program evaluation constructed by us, we went on to make an investigation and our research assumption that the program "Basics of Camera" made a good performance. In the experiment, researcher was issued 15 questionnaires to the subjects. The questionnaires were divided into four evaluation levels including "excellent", "good", "medium" and "poor". And then, based on these questionnaires, we analyzed and calculated scores of every index and overall score of the program quality.

According to the formula of scoring average $W i=\left(\sum^{*}\left(a_{i} \times n_{i}\right)\right) / a_{h} \times N$, we made $W i$ multiplied the weight of every index in order to get the scores of every index. In the formula, "ai" is the score of every level, " $n i$ " is the population, ah is the highest score and $N$ is the total population (see Table III).

TABLE III: STATISTICS OF WHICH THE EXPERIMENT VOLUNTEERS SHOWS TO THE QUALITY EVALUATION RESULTS OF TV

\begin{tabular}{|c|c|c|c|c|c|c|c|c|c|}
\hline \multirow{2}{*}{$\begin{array}{c}\text { Level } \\
\text { indicators }\end{array}$} & \multirow{2}{*}{$\begin{array}{l}\text { Secondary } \\
\text { indicators }\end{array}$} & \multirow{2}{*}{$\begin{array}{c}\text { Third } \\
\text { indicators }\end{array}$} & \multirow{2}{*}{$\begin{array}{l}\text { Weights of } \\
\text { individual } \\
\text { indicators }\end{array}$} & \multicolumn{4}{|c|}{ Rank } & \multirow[b]{2}{*}{ Wi } & \multirow[b]{2}{*}{$\mathrm{Fi}$} \\
\hline & & & & E & $\mathrm{G}$ & M & P & & \\
\hline \multirow{6}{*}{$\begin{array}{c}\text { Instruction } \\
(58 \%)\end{array}$} & \multirow{3}{*}{$\begin{array}{l}\text { Instructional } \\
\text { design } \\
(43 \%)\end{array}$} & Purpose & 21 & 9 & 4 & 2 & 0 & 0.87 & 18.2 \\
\hline & & Pedagogy & 14 & 4 & 9 & 2 & 0 & 0.78 & 10.97 \\
\hline & & Objects & 8 & 4 & 8 & 3 & 0 & 0.77 & 6.16 \\
\hline & \multirow[t]{3}{*}{$\begin{array}{l}\text { Instructional } \\
\text { practice } \\
(15 \%)\end{array}$} & $\begin{array}{l}\text { Theory } \\
\text { guideline }\end{array}$ & 7 & 8 & 5 & 2 & 0 & 0.85 & 5.95 \\
\hline & & Activities & 5 & 7 & 5 & 3 & 0 & 0.82 & 4.08 \\
\hline & & Media & 3 & 6 & 7 & 2 & 0 & 0.82 & 2.45 \\
\hline \multirow{6}{*}{$\begin{array}{c}\text { Interactivity } \\
(28 \%)\end{array}$} & \multirow{3}{*}{$\begin{array}{c}\text { Interactive } \\
\text { design } \\
(18 \%)\end{array}$} & Module design & 8 & 1 & 8 & 5 & 1 & 0.65 & 5.2 \\
\hline & & $\begin{array}{l}\text { Navigate } \\
\text { strategies }\end{array}$ & 6 & 5 & 10 & 1 & 0 & 0.87 & 5.2 \\
\hline & & $\begin{array}{l}\text { Interactive } \\
\text { function }\end{array}$ & 4 & 4 & 6 & 5 & 0 & 0.73 & 2.93 \\
\hline & \multirow{3}{*}{$\begin{array}{c}\text { Interactive } \\
\text { contents } \\
(10 \%)\end{array}$} & $\begin{array}{l}\text { Interactive } \\
\text { resources }\end{array}$ & 5 & 5 & 7 & 3 & 0 & 0.78 & 3.92 \\
\hline & & $\begin{array}{l}\text { Types of } \\
\text { resources }\end{array}$ & 3 & 4 & 10 & 1 & 0 & 0.8 & 2.4 \\
\hline & & $\begin{array}{c}\text { Resources } \\
\text { design }\end{array}$ & 2 & 8 & 5 & 1 & 1 & 0.83 & 1.67 \\
\hline \multirow{6}{*}{$\begin{array}{l}\text { technique } \\
(14 \%)\end{array}$} & \multirow{3}{*}{$\begin{array}{l}\text { Technological } \\
\text { support } \\
(7 \%)\end{array}$} & $\begin{array}{l}\text { Software } \\
\text { support }\end{array}$ & 3 & 5 & 8 & 2 & 0 & 0.8 & 2.4 \\
\hline & & $\begin{array}{l}\text { Hardware } \\
\text { support }\end{array}$ & 2 & 6 & 8 & 1 & 0 & 0.83 & 1.67 \\
\hline & & Stable support & 2 & 6 & 5 & 3 & 1 & 0.77 & 1.53 \\
\hline & \multirow{3}{*}{$\begin{array}{l}\text { Technological } \\
\text { application } \\
\text { (5\%) }\end{array}$} & $\begin{array}{l}\text { Practice } \\
\text { support }\end{array}$ & 3 & 5 & 8 & 1 & 1 & 0.78 & 2.35 \\
\hline & & $\begin{array}{c}\text { Performance } \\
\text { support }\end{array}$ & 1 & 8 & 5 & 2 & 0 & 0.85 & 0.85 \\
\hline & & Media support & 1 & 6 & 6 & 2 & 1 & 0.78 & 0.78 \\
\hline
\end{tabular}

We gained the score of every index after the statistics of questionnaire evaluation. With these work done, we calculated the establishment quality of the program "Camera basic skills" that was Fi equal to 81.07. According to the levels, the poor level is below 60scores, the medium is between 61 and 75 scores, the good level is between 76 and 85 scores, and the excellent level is more than 86 scores. So 
we made a conclusion that this program quality was good.

\section{B. Discussion}

Through the investigation, we found that these three indicators at first class in the index system distributed uneven.

For the aspect of Instruction, many people thought that the "Camera Basic Skills" TV program quality level was "excellent" for the indexes of "purpose" (9/15), "theory guideline" (8/15), and "activities" (7/15). The indexes of "Pedagogy" (9/15), "objects" (8/15), and "activities" (7/15) were "good" level. This is proof that the instruction of TV program has attained good performance that students have got good learning practice during watching program.

For the aspect of interactivity, just the index of "resources design" (8/15) level was "excellent", but there is a different view thought the index of "resources design" (1/15) was "poor". Many people thought that the index of "module design" (8/15), "navigate strategies" (10/15), "interactive function" (6/15), "interactive resource" (7/15), and "types of resources" were "good". This is demonstrated the TV program also give a good practice in terms of interaction.

For the aspect of technique, many people thought that the indexes of "performance support" $(8 / 15)$ was "excellent" and the indexes of "software support"(8/15), "hardware support"(8/15), "practice support"(8/15), and "media support" were "good". This is proof that the flexibility of the television program on support different system, platform, and devices is good.

The instructive index was weighted at 58 percentages, and the rest of two was 28 percentages and 14 percentages. It indicated that we should design the index more scientific and reasonable in the future research.

\section{CONCLUSION}

This research is aim to design and apply the Interactive digital educational TV program during the higher education learning process. After literature review about cognitive load theory, educational television, and interactive digital educational TV program, there are three research questions have been proposed as below:

1) How to design an interactive educational television program which can meet the requirement of the learners who are learning the subject of "Television program composition" in SCNU?

2) How to apply the developed interactive television in the teaching process to promote students` television shooting skills?

3) How to test the developed interactive television program is indeed skills effective and attitude positive for students when they have watched the learning resource?

Thought about interactive educational television program is a kind of learning resource, the ADDIE model has been chosen to give the research guideline which is design and apply alone with the ADDIE five steps (analysis, design, develop, implement, and evaluation). This research has designed the "Camera basic skills" interactive educational TV program for undergraduate students of SCNU.

During the application phase, the Interactive Navigation Process (INP) has been chosen to apply the developed interactive TV program through the teaching process of the class "Designation and application an educational TV program" in college of educational information technology of SCNU.

Finally, there is an evaluation index system to test the effective for learning about this interactive educational TV program. All in all, after the experiment and data analysis process, the volunteers of this research have given good evaluation to every index generally. This indicate that the students indeed have the willing to have a try watching and operating the interactive television, and also TV program can meet the requirement of learners' and the demand of instructional design. For the index of "instruction" of evaluate system attain good level generally, this TV program has equipped the capacity of instructional design and instruction practice. So that it can help students` long-term memory during watching process. For the index of "interactivity" of evaluate system attain good level generally, this TV program can give good interactive practice with students in terms of devices and resources. For the index of "technique" of evaluate system attain good level generally, this TV program has equipped the technological flexibility during the process of applied.

In this research, statistics has showed the good level of the program quality and effect based on the ADDIE model. But, there was lack of good TV program resources, so that the future research should make the television programs on our own in the later research.

The development process models of the Interactive digital educational television program provide a reference for Resource development process of interactive television. At the same time, the Interactive Navigation Process (INP) has provided possibility for personalized, interactive of the learning styles of the Interactive TV resources. Based on the learning characteristics of learners, the theory of human-computer interaction, instructional design theory, this study has proposed the TV resources design model. The follow-up study will focus on the development and application of resources with the TV, and this will provide possible reference ideas for the development and application of interactive digital educational television program resources of ADDIE model.

After the analysis, the data indicated that the interactive educational TV program has achieved good performance on the three aspects (instruction, interactivity, and technique) of evaluation index system. So that the conclusion that "Camera basic skills" interactive educational TV program is effective for undergraduate students on the three aspects of instruction, interactivity, and technique can be found.

\section{ACKNOWLEDGMENT}

This research would thank for the help of the teachers X. W. Li, X. Y. Lin, and the students who participated in this research. In addition, the researcher would gratefully acknowledge the help and support by professors $\mathrm{F}$. Y. Xu, P. Z. Wu and X. Y. Hu.

\section{REFERENCES}

[1] H. Wiphasith, R. Narumol, and C. Sumalee, "The design of the contents of an e-learning for teaching M.5 English language using 
ADDIE model," International Journal of Information and Education Technology, vol. 6, no. 2, pp. 127-131, February 2016.

[2] J. S. Lim, S. Y. Ri, B. D. Egan et al., "The cross-platform synergies of digital video advertising: Implication for cross-media campaigns in television, Internet and mobile TV," Computers in Human Behavior, vol. 48, pp. 463-472, 2015

[3] C. P. Ong and Z. Tasir, "Self-instructional teaching module based on cognitive load theory: A study on information retention among trainee teachers," Educational Technology Research \& Development, 2015, pp. 1042-1629.

[4] J. Sweller, "Cognitive load during problem solving: Effects on learning," Cognitive Science, vol. 12, no. 2, 1988, pp. 257-285.

[5] S. Kalyuga, "Cognitive load theory: How many types of load does it really need?" Educational Psychology Review, vol. 23, no. 1, 2011, pp. $1-19$.

[6] F. Paas and P. Ayres, "Cognitive load theory: A broader view on the role of memory in learning and education," Educational Psychology Review, vol. 26, no.2, 2014, pp. 191-195.

[7] F. Bellotti, R. Berta, A. D. Gloria et al., "Investigating the added value of interactivity and serious gaming for educational TV," Computers \& Education, vol. 57, no. 1, 2011, pp. 1137-1148.

[8] M. L. Z. Abascal, "Transmedia intertextualities in educational media resources: The case of BBC schools in the United Kingdom," New Media \& Society, June 2015.

[9] D. M. Fu and L. T. Zhang, "Applied research CNKI perspective of educational television," E-Education Research, 2005, pp. 66-69.

[10] A. M. Moses, D. B. Golos, and C. M. Bennett, "An alternative approach to early literacy: The effects of ASL in educational media on literacy skills acquisition for hearing children," Early Childhood Education Journal, 2015, pp. 1-10.

[11] F. Y. Xu, M. X. Huang, and G. J. Ren, "The digital educational television program production and application," E-Education Research, 2004, pp. 65-69.

[12] M. X. Huang, X. Y. Lin, and X. B. Zhang, "The application of digital educational television programs and innovation to promote research," China Educational Technology, vol. 2, 2010, pp. 69-73.

[13] J. F. Jensen, "Interactive television: new genres, new format, new content," in Proc. the Second Australasian Conference on Interactive entertaINPent, Creativity \& Cognition Studios Press, 2005, pp. 89-96.
[14] S. C. Wang, T. C. Chung, and K. Q. Yan, "A new territory of multi-user variable remote control for interactive TV," Multimedia Tools \& Applications, vol. 51, no. 3, 2011, pp. 1013-1034.

[15] F. Garzotto, "Was vygotsky right? Evaluating learning effects of social interaction in children Internet games," Human-Computer Interaction - Interact 2007, Heidelberg, Berlin: Springer, 2007, pp. 376-389.

[16] I. Ekman and P. Lankoski, "Integrating a game with a story - Lessons from interactive television concept design," Computers \& Graphics. vol. 28, no. 2, 2004, pp. 167-177.

[17] M. X. Huang, "Model of innovative applications of digital educational television programs," China Educational Technology, vol. 5, 2010, pp. 69-73.

[18] Redondo, R. P. Díaz et al., "TV guide2.0: Applying the web2.0 fundamentals to IDTV," IEEE on Computers in Education International Conference, 2009, pp. 1-2.

[19] M. Molenda, "In research of the elusive ADDIE model," Performance Improvement, vol. 42, no. 5, 2003, pp. 34-36.

[20] K. D. Li, Educational Technology Research Method, Beijing: Beijing Normal University Present, 2001, pp. 284-285.

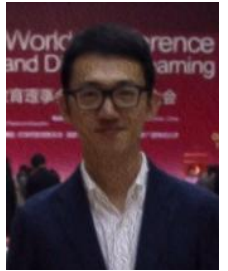

Zixun Hua was born in Chaoyang, Liaoning province, China in 1987. He received his B.Sc. and M.Sc. degrees in 2006 and 2014 respectively from the East China Jiaotong University and South China Normal University. Now, he is study for educational technology's Ph.D. degree in SCNU.

During the studying process, he published some papers about e-learning resources, like "The development and application research of education master's network course based on the analytic hierarchy process" on the $25^{\text {th }}$ ICDE World Conference for Open Distance Education, and "The design research based on the interactive navigation process for interactive educational television program" on the 2012 Chinese International Conference for Educational Technology. His research interests are educational television, MOOCs, SPOCs, and flipped classroom. 